\title{
EQUITY IN HEALTH: A REVIEW OF DISPARITIES AMONG MĀORI PRE AND POST CULTURAL SAFETY EDUCATION/ KAWA WHAKARURUHAU IN NEW ZEALAND
}

\author{
Erana Heperi
}

\section{INTRODUCTION}

Equity in health is expressed as the absence of avoidable or remedial differences throughout various collectives, regardless of those collectives being defined socially, economically, demographically, or geographically (World Health Organisation, 2020). The concept acknowledges that not only are differences in health status unfair and unjust, but they are also the result of differential access to the resources necessary to lead healthy lives. Māori occupy a unique position in New Zealand society. As Tangata Whenua, an indigenous minority, and a group facing particular economic disadvantage, the social position of Mãori has frequently been the focus of public discussion and debate. The purpose of this paper is to consider the journey of New Zealand's indigenous population through the health system, discussing relevant events such as the Māori cultural renaissance, biculturalism, health reform and the influence of Te Tiriti $\circ$ Waitangi in tino rangatiratanga and the preservation of taonga (Wepa, 20I5; Ministry of Health $[\mathrm{MOH}], 2020)$. The aim is then to compare past and present health inequities to identify variation or change with the introduction of Cultural Safety. Health disparities will be identified with the use of health status indicators, specifically morbidity, mortality, use of health services, socioeconomic status and life expectancy.

\section{CLINICAL ENVIRONMENT}

During my course of study for a Bachelor of Nursing degree, it became exceedingly obvious that in many ways, Māori are at a disadvantage. A significant disadvantage which reverberates through many aspects of contemporary society. Healthcare is one of many areas which is highly emotive and provokes significant concern for Mãori. The story of health for Māori is one of systemic disparities in health outcomes, in determinants of health, in health system responsiveness and representation in the health workforce (Reid \& Robson, 2006). In almost every major disease category, Māori bear a disproportionate burden of risk, morbidity, disability, and mortality (Heather, Dominic, Jacque, \& Timothy, 2020). My personal experience of such inequity comes not only from being Māori, but also through working with Māori during placement. Education received by students during a Bachelor of Nursing may be considered supportive but superficial and does not address the broader issues at play. Furthermore, student colleagues often struggle to meet the Nursing Competencies (2012) 1.2 \& 1.5, specific to Māori and Te Tiriti and are unsure how to provide evidence of working meaningfully with Māori consumers (Nursing Council New Zealand, 2012). This led to a personal inquiry of the effectiveness of cultural safety in attending to the more complex needs of Māori and raises the question, does the health system operate in a way which respects Te Tiriti by working in a collaborative partnership with Tangata Whenua? 


\section{HISTORICAL OVERVIEW}

In order to analyse the present health status of the indigenous population, a brief study of the past is required. It is impossible to separate the historical colonial context from the contemporary health status of Māori. National and international research has long documented the negative impact of colonisation to indigenous populations worldwide (United Nations, 2009). The arrival of Pākehā to Aotearoa not only brought disease, conflict and dispossession but also caused the destruction of indigenous belief and value systems (Reid \& Robson, 2006). Exposure to infectious disease with no prior immunity or relative coping mechanisms led to a decline in the population by one third. Dispossession of land not only increased the likelihood of poverty but also susceptibility to disease, overcrowding and malnutrition. It dismantled social networks which aided practical and emotional support in times of need (Pōmare, 1995).

A significant advantage for Māori in contrast with indigenous counterparts throughout the world, is the signing of Te Tiriti o Waitangi, despite long being viewed as a point of contention for Māori. Te Tiriti is now recognised by governing bodies as the most critical document for Mãori, to correct inequity. Te Tiriti symbolises a promise of protection and a guarantee to the same right and privileges as British subjects (Wepa, 2015). Unfortunately, it has been a promise unkept but one that Māori continue to hold the Crown accountable to. Rising tensions and debate during the late 1960s and 1970s, is marked by the phrase 'honour the treaty'. Many Māori and Pākehā activists believed the Treaty to be fraudulent due to the neglect of Crown obligations (Came, Doole, McKenna \& McCreanor, 2018). Due to the breaches of Te Tiriti, activist groups protest for equity and the right to live as Mãori. The formation of the Waitangi Tribunal in 1975, provided a platform for claims against the treaty, pushed largely by urban activism of Māori to address the social and economic impacts of legislative induced poverty.

Later in 1986, the Ministry for Social Welfare was directed to investigate Māori perspectives of welfare. The report produced by the Ministerial Advisory Committee (200I) opposed racial discrimination present in governmental bodies and provided a catalyst for the introduction of biculturalism (New Zealand Parliament, 2009; Wepa, 2015). Before this, Aotearoa was unofficially a monocultural society. The renaissance of Māori culture and the implementation of biculturalism resulted in a further restructuring of the health system. A bicultural society is a theory of two cultures coexisting equally - a theory supported by the Treaty maintaining a platform for a negotiated partnership. True biculturalism is about sovereignty. According to Durie, "biculturalism exists when - values and traditions of both cultures are reflected in society's customs, laws, practices, and institutional arrangements, with both sharing control over resources and decision making" (1998, p. I0I).

Aotearoa underwent a series of significant health system reforms throughout the 20th century, mirrored around the world, which resulted in several benefits but also highlighting inconsistencies and disparities among specific population groups (Gauld, 2003; New Zealand Parliament, 2009). Basic healthcare structures developed early during the colonial history, and transitional changes during the health reforms saw the development of local hospital boards, regional authority-based structures for public health monitoring and surveillance. The most potent stimulus of health reform was the economic downturn in the 1980s. Global financial changes and loss of access to specific markets led to a significant impact on the economy and subsequently, the provision of the welfare state. The changes in welfare drew attention to a disparity, showing an inability of specific groups within the population, to access healthcare services and to pay for the increase in fees (Gauld, 2003; Ross, 2017). At that time, Māori represented more than $40 \%$ of those utilising the welfare service.

\section{HEALTH ISSUE}

Health status is measured by monitoring factors such as life expectancy, mortality, morbidity hospital and General Practice service utilisation. A well-known criticism of the conventional measurement of health status is its limitation to only identify death and illness rates, rather than the measurement of health and wellbeing (Statistics New Zealand, 1994). Statistics collected by government agencies are, in general, quicker and less costly, compared 
to lengthy self-assessment surveys that are difficult to collect and analyse. However, despite their limitations, conventional methods of data collection show strength through critical identification of trends over a period of time. While stand-alone rates of morbidity or mortality can be rightly criticised as an incomplete overview of health status, serial measurements over time, in conjunction with additional relevant data, the statistics are likely to provide a more complete and accurate overview.

A review of relevant indicators between 1970 to 199 | revealed: mortality - the death rate for Māori in almost all major causes continued to decrease alongside non-Māori. However, a difference between populations remained, regarding the rate of sudden infant death syndrome, youth suicide, homicide, violence; and motor vehicle accidents (Statistics New Zealand, 1994; Pōmare, 1995). A reduction in the death rates from asthma and coronary heart disease also decreased but overall remained disproportionate to non-Māori (Pōmare, 1995). Cancer bwas the leading cause of death during this period. Morbidity - relevant to mortality, the rate of hospital admissions for Māori increased for almost all disease categories; the primary causes for admission were asthma, unintentional injury, motor vehicle accidents, ear disease, respiratory and heart disease. Admissions to psychiatric services increased for Māori, compared to a decline in non-Māori, where alcohol dependence or abuse remained the leading cause for admissions in males and the second most common cause among Māori women. Drug dependence or abuse was the third cause of admission for Māori men (Pōmare, 1995). Māori also accessed health services later than non-Māori, equating to more severe symptoms of illnesses before help was sought.

An additional and vital indicator of health is socioeconomic status; whereby the colonial and political impacts for Māori and subsequent disparities are evident. Determinants of health include aspects of income, employment, housing, education, family structure and lifestyle practices. Trends from that time indicate Māori became worse off compared to non-Māori (Statistics New Zealand, 1994; Pōmare, 1995). Unemployment was particularly high among Māori (24.2 percent compared to percent non-Māori) affecting levels of income, directly impacting access to healthcare. Māori males received an annual median income of $\$ 12,995$, less than two thirds than that of nonMāori. Furthermore, percent of Māori had no assets compared to percent of non-Māori. During this period, we also saw an increase in solo parent family structures from percent in 1981 to percent in 1991. Positively, there were improvements observed in education where in 1993, 34 percent of Māori exited school without a formal qualification, compared to 53 percent in 1986. This is closely associated with the Kōhanga Reo movement catering for 49 percent of Māori in 1993; however, youth continued to be at risk of exiting early compared to non-Māori. In terms of housing, 40 percent of Māori were living in rented accommodation compared to 21 percent of non-Māori (Statistics New Zealand, 1994). Prominent trends within literature demonstrate the socioeconomic position of the Māori during this period and directly impact health status.

\section{Status Quo}

Equity in health is defined as 'differences in health that are unnecessary, avoidable, unfair and unjust' (Whitehead, 1992 p.43I). In the 2 Ist century, it is not difficult to assess the health status of contemporary Māori, as relevant literature carries trends consistent with the previous decades. The negative impacts of a system which supports values and beliefs of the dominant group has seen inequity echoed through many of society's institutions. Māori are significantly over-represented in literature relating to mortality and morbidity, in addition to maintaining a lower socioeconomic position. It is supplemented by disproportionate representation in social sectors of welfare, unemployment, justice and corrections. Simultaneously, Māori are under-represented in significant roles in society which would affect positive political and systematic change for Mãori, as well as other minority groups. The current health system does not meet the specific needs of minority groups, and the quality of service is variable, despite efforts of the successive government for change since 1938 (Matheson et al., 2013).

In 1988, the Health Funding Authority appointed eight priority areas of importance for Māori development $(\mathrm{MOH}, 2000)$. Although there are many areas of need in Māori health, the following were identified as the most concerning at that time. Priority areas identified were mental health, diabetes, immunisation, injury, oral health, 
hearing, smoking and asthma. Conversely, at present many of the previous health priories remain. A study in 2003/04 found that just over half of Māori had experienced a mental disorder during their lifetime, and sustained higher rates of serious disorders than Pasifika, non-Māori and non-Pasifika peoples (Baxter, 2007). Māori are disproportionately burdened by non-communicable disease processes such as cardiovascular disease and the ensued complications. In 2002/03 the prevalence for self-reported diabetes among adults was 6.9 percent for Māori males and 5.I percent for Māori females, compared to 2.6 percent and 2.I percent in non-Māori respectively (Harwood \& Tipene-Leach, 2007). In 2000-04, respiratory diseases were one of the five leading causes of death and hospitalisation for Māori (Curtis, Harwood \& Riddell, 2007).

More current statistics show Māori have one of the highest age-standardised rates of Emergency Department [ED] use (I8.0 per 100 population) during 20/4/I5, second to pacific island people. According to Ministry of Health (2016), ED service utilisation rates increase with each level of neighbourhood deprivation, the lowest decline being the least deprived and the highest being those most deprived or those of a low-socioeconomic status. Māori ethnicity is an important risk factor, where the prevalence of diabetes among Māori is three times higher than nonMāori, attributable to obesity and neighbourhood deprivation (MOH, 2018a, 2019a). Māori are diagnosed at a younger age and are more likely to develop complications of diabetes such as stroke and heart disease contributing to a higher rate of diabetes related death for Māori. Recent statistics (2017/18) reveal 47 percent of Māori adults are obese up from 44 percent in 2011/12 (MOH, 20l3, 20l8b). A higher proportion of Māori live in deprivation and those living in the most deprived areas of New Zealand are over 1.5 times more likely to be obese $(\mathrm{MOH}$, 20।8b). Māori and Pasifika have 25 percent lifetime risk of developing diabetes compared to European (Farrell \& Dempsey, 2011).

In 2015, the mortality rate for ischemic heart disease in Māori was twice that for non-Māori. The Ministry of Health (2019b, 2019c) state that from 2006-2015, there was a decline in the number of fatal and non-fatal ischemic heart disease, however, Māori remain disproportionately high in mortality $(\mathrm{MOH}, 2019 \mathrm{~b}, 2019 \mathrm{c})$. According to the Health Survey 2017/18, reported stroke was 2.7 times more likely in Māori women, than non-Māori women. In general, rates of stroke mortality have decreased by 62 percent since 198I, however Māori experience a slower rate of decline and suffer stroke at a younger age than non-Māori. During 2016, Māori men and women have higher rates of new cancer registration than non-Māori. Furthermore, Māori experience a higher rate of death from cancer than non-Maori (MOH, 2019b, 2019c). Māori also experience significantly higher rates of mental illness, higher rates of suicide and greater prevalence of addiction. While the prevalence of mental distress among Māori is almost 50 per cent higher than non-Māori, Māori are 30 per cent more likely than other ethnic groups to have their mental illness undiagnosed (New Zealand Mental Health and Addiction Inquiry, 20I8; MOH, 2020). The implications of decolonising health systems and Crown breaches of Te Tiriti, demonstrate that current systemic and legislative policy frameworks do not go far enough to ensure the whole system complies with Te Tiriti, undermining tino rangatiratanga and furthermore, the current 'treaty principles' have been found to be antiquated, and require a more elaborate approach (Heather, Dominic, Jacque, \& Timothy, 2020).

\section{IMPLICATIONS}

The aim is not to condemn the continuation of health inequities or validate the need for Māori health-focused interventions, as this is well researched and echoed worldwide (Durie, 1998; United Nations, 2009). The aim is to discuss mechanisms for change, such as biculturalism and cultural safety and ascertain if such interventions have influenced a positive systematic change in disparities. Health equity is defined as "the absence of systematic disparities in health, or in the determinants of health, between different social groups who have different levels of underlying social advantage/disadvantage, that is, different positions in a social hierarchy" (Braveman \& Gruskin 2003, p.254). For Reid and Robson (2006) the national and international evidence demonstrating ethnic health inequities are strong; however, this information is often ignored due to absent or poor-quality ethnicity data or a data set not being analysed by ethnicity. Additionally, inequities are only briefly mentioned rather than undergoing 
frank and robust discussions. Consequences related to not fully exploring or understanding the reasons why such disparities exist are significant, as the status quo will remain and disparities between groups may continue to increase (Reid \& Robson, 2006; Matheson et al., 2013). This approach to literature supports a superficial understanding of the cause of disparities. Critically, this can be viewed as a lack of commitment to attend to these issues, and furthermore, prevents wider communities from being fully informed.

Improving health disparities is dependent on a combination of socio-political factors, most of which begin well outside the clinical setting. Significant health improvements are unlikely unless current methods are re-examined to incorporate a political and intersectoral shift in clinical practice, legislation, and national strategy (Matheson et al., 2013; Hogarth \& Rapata-Hanning, 2019). A focal theme in colonisation is the belief in white superiority, which stems from an ethnocentric ideology (Germov, 2014). Unless the negative impacts embedded in the process of colonisation are acknowledged as deliberate, it is easy to assume that colonisation is something accidental or inevitable or something of the past rather than a major influence on contemporary society. Rationalisation of inequity for Māori has involved the use of theories such as deficit theory or victim-blaming, where the issues experienced among Māori are attributed to inferior genetics, education, aptitude, ability, effort or luck (Reid \& Robson, 2006).

This type of oppressive ideology is circulated and reverberates throughout communities, impacting attitudes of those delivering health services and the quality of care received. Ignoring structural and systemic bias, despite current literature highlighting Māori experience a deficit in access to health services, means ethnic inequity is likely to continue. In a study by Curtis et al. (2019), evidence indicated pro-NZ European bias among medical students, with most respondents indicating some level of preference for Europeans with positive compliance attributes relative to Māori. This aligns with international studies that find bias favouring the dominant racial/ethnic group among medical students and other health providers. If nurses, practice with an ideology or misconception of Māori being undeserving, or that Māori are rightly positioned as they are, due to lack of effort, compliance or aptitude; these nurses prevent Māori from achieving their aspirations for health and wellbeing. This approach impacts the opportunity for all New Zealanders to live their healthiest lives despite one's specific needs or position in the social-economic hierarchy, thus dishonouring Te Tiriti (Matheson et al., 2013).

\section{DISCUSSION}

For Came et al. (2018), the New Zealand government has long been accused by activist scholars who work to expose mono-culturalism and institutional racism. The government's response to activism and protest in the 1970s, concerning the neglect of the treaty obligations, was to introduce bicultural practices in society. From this came an induction of aspects of Māori culture dispersed through the healthcare sector. This involved the facilitation of pōwhiri, karakia, mihi whakatau and poroporoaki. This movement saw the creation of Māori liaison teams and Kaiāwhina within DHB to fulfil cultural requirements. The presence of Māori was being acknowledged, and the culture was partially integrated throughout society. Pākehā discovered a newfound acceptance for Māori Tikanga, implementing a protocol for the use of different coloured towels for washing of the body and head. The change was significantly therapeutic for Māori, symbolising a long sought-after partnership and collaborative approach ascribed by Te Tiriti. However, now well into the 2 lst century, Māori continue to encounter premature mortality, and in almost every major disease category, Māori are disproportionately affected compared to nonMāori. In some categories, the disparity has become worse (Reid \& Robson, 2006; MOH, 2019a). This raises the question, has biculturalism been effective in restoring equity for Māori?

Cultural safety is a more appropriate intervention and mechanism for change. Introduced by Dr Irihapeti Ramsden in the 1980s, a framework which implores nurses to consider their own culture and bias when working with Māori, extending beyond cultural competence and sensitivity (Wepa, 2015). It evokes analysis of one's values and beliefs and requires acknowledgement of the practitioner's position of power and the potential they possess to hinder 
service delivery. It is a significant contribution to nursing education and an important tool which helps identify underlying issues relating to interpersonal racism, discrimination, or preconceptions a practitioner may not even be aware they possess. Curtis et al. (2019), argue that cultural safety rather than cultural competence or sensitivity should be implemented not only across various medical disciplines but through a multi-sectoral approach to partnership with Māori, for its capacity to assess and highlight prejudice (Robinson, Kearns \& Dyck, 2007).

For Curtis et al, (2019) the investment in Mãori culture has not addressed inequity - "It is not a lack of awareness about 'the culture of other groups' that is driving health care inequities - but rather the unequal power relationships, unfair distribution of the social determinants of health, marginalisation, biases and unexamined privilege" (p.2). Came (2012) asserts racism as a determinant of health, one that remains unacknowledged and the growth in evidence associates ethnic disparities with racism and privilege. Practitioners should be prepared to challenge their own culture and cultural systems rather than focus on becoming "competent" in other cultures. Cultural safety introduces the conversation of racism and privilege since its introduction to nursing; however, inequities persist $(\mathrm{MOH}, 20 / 8 b)$. This framework should be utilised as a baseline for collaborative partnership; it is not the solution for inequities but a catalyst for change.

\section{RECOMMENDATIONS}

Literature relating to barriers in access to healthcare for Mãori is overwhelming, with the most critical determinant being institutional racism. "Honouring Te Tiriti is a pathway to transforming racism" (Came, 20I2, p.2). The eradication of structural racism, along with improvements in autonomy arrangements with Māori is essential. Māori are well equipped to be strategic collaborators with the health sector with significant insight $(\mathrm{MOH}$, 2019a). This type of adjustment is likely to encounter resistance; however, this is not a credible reason to weaken the necessity for change. Removing institutional racism should be driven by leaders in the professional bodies, unions, and our communities. Systematic efforts should be made to remove policies, practices, and leadership, which enable institutional racism in health (Chin et al., 20I8). Support should be given to the facilitation of free, frank and fearless discussions about colonial history, structural racism, privilege and bias to develop policies and frameworks which explicitly address root causes. Unfortunately, new policy development often does not align with evidence-based approaches known to improve equity. A review of the New Zealand Health Strategy $(\mathrm{MOH}, 2016)$ found that the health system often relies on the isolated efforts of committed individuals and organisations to achieve health equity rather than through a planned systems method (Came, Creanor, Doole \& Rawson, 2016).

Literature relevant to equity and Te Tiriti applications reports that efforts should be sustained, systematic and multi-levelled, rather than ad hoc and piecemeal. An authentic, committed, and coordinated approach is required. The new Māori Health Action Plan - Whakamaua, has prioritised achieving equity and the elimination of racism and discrimination in the health and disability system. This document states "achieving equity for Māori will require all contributors to health to acknowledge inequitable health outcomes for Māori as not only unfair and unjust but also avoidable" (MOH, 2020 p.32). This action plan has highlighted that the attainment of equity lies in resource prioritisation for Māori and embedding cultural safety system wide, with all contributors being encouraged to acknowledge and address their own attitudes and bias.

\section{CONCLUSION}

Evidence provided in this paper is consistent with research from the last four decades, that for Māori, health inequities have not changed. In many ways, these disparities have worsened compared with non-Māori counterparts. The purpose of this paper is to consider the effectiveness of mechanisms for change, such as cultural safety in the betterment of Māori health outcomes. While achieving equity for Māori, Pasifika, and lowsocioeconomic populations is a priority, addressing policy and service barriers that cause inequities will benefit 
many minority groups that suffer inequities in health. A multi-sectorial approach is required, that often begins well outside the clinical setting. Biculturalism and cultural safety mark significant contributions to Māori health development, prescribing collaboration between parties; however, as inequities remain constant, the conversation needs to continue.

\section{ACKNOWLEDGMENTS}

To the many academic scholars and health professionals, both Māori and non-Māori, for their valuable contributions to health and kaupapa Māori research and literature. Many authors have helped shape my perspective as a student and as a future nurse.

Erana Heperi, of Ngāpuhi descent, is a Bachelor of Nursing student at Otago Polytechnic. Nursing areas of interest are Emergency and Trauma, Public Health, Forensics, Mental Health and Addictions, Research and Māori Health Development.

Correspondence to: Erana Heperi, School of Nursing, Otago Polytechnic | Te Kura Matatini ki Otago, Forth Street, Private Bag 1910, Dunedin 9054, New Zealand. Email: Erana.Heperi@gmail.com

\section{REFERENCES}

Baxter, J. (2007). Mental health: Psychiatric disorder and suicide. In B. Robson \& R. Harris (Eds). Hauora Māori standards of health IV. A study of the years 2000-2005. Wellington: Te Rōpū Rangahau Hauora a Eru Pōmare.

Braveman, P., \& Gruskin, S. (2003). Defining equity in health. Journal of Epidemiology \& Community Health, 57(4), 254-258. doi: 10.1136/jech.57.4.254

Came, H. A. (2012). Institutional racism and the dynamics of privilege in public health. [Unpublished Doctoral dissertation, University of Waikato]. Retrieved from http://www.communityresearch.org.nz/wp-content/uploads/formidable/ community-research-version.pdf

Came, H., Creanor, T., Doole, C., \& Rawson, E. (2016). The New Zealand Health Strategy: Whiter health equity? New Zealand Medical Journal, 129(1447), 72-77.

Came, H., Doole, C., McKenna, B., \& McCreanor, T. (2018). Institutional racism in public health contracting: Findings of a nationwide survey from New Zealand. Social Science \& Medicine, 199, 132-139. doi: 10.1016/j.socscimed.2017.06.002

Chin, M., King, P., Jones, R., Jones, B., Ameratunga, S., Muramatsu, N., \& Derrett, S. (2018). Lessons for achieving health equity comparing Aotearoa/NewZealand and the United States. HealthPolicy, 122(8), 837-853. doi: 10.1016/j.healthpol.2018.05.001

Curtis, E., Harwood, M., \& Riddell, T. (2007). Cardiovascular disease. In B. Robson \& R. Harris (Eds). Hauora Māori standards of health IV. A study of the years 2000-2005. Wellington, New Zealand: Te Rōpū Rangahau Hauora a Eru Pōmare.

Curtis, E., Jones, R., Tipene-Leach, D., Walker, C., Loring, B., Paine, S., \& Reid, P. (2019). Why cultural safety rather than cultural competency is required to achieve health equity: A literature review and recommended definition. International Journal for Equity in Health, 18(1). doi: 10.1186/s/2939-019-1082-3

Durie, M. (1998). Te mana, te kawanatanga: The politics of Maori self-determination. Auckland, New Zealand: Oxford University Press.

Durie, M. (1998). Whaiora: Māori health development (2nd ed.). Auckland, New Zealand: Oxford University Pressen/SOWIP_ web.pdf 
Farrell, M., \& Dempsey, J. (20II). Smeltzer \& Bare's textbook of medical-surgical nursing: Volume 2. Broadway, N.S.W.: Lippincott Williams.

Gauld, R. (2003). Revolving doors. Wellington, New Zealand: Victoria University of Wellington.

Germov, J. (Ed.). (2014). Second opinion: An introduction to health sociology (5th ed.). Melbourne, Australia: Oxford University Press.

Harwood, M., \& Tipene-Leach, D. (2007). Diabetes. In B. Robson \& R. Harris, (Eds). Hauora Māori standards of health IV. A study of the years 2000-2005. Wellington, New Zealand: Te Rōpū Rangahau Hauora a Eru Pōmare.

Heather, C., Dominic, O., Jacque, K., \& Timothy, M. (2020). The Waitangi Tribunal's WAI 2575 report: Implications for decolonising health systems. Health And Human Rights Journal, 22(I), 209-220. Retrieved from https://www.ncbi.nlm.nih. gov/pmc/articles/PMC7348423/pdf/hhr-22-0I-209.pdf

Hogarth, K. \& Rapata-Hanning, M. (2019). Māori health in Aotearoa New Zealand. In S. Huether, K. McCance, V. Brashers, \& N. Rote (Eds). Understanding pathophysiology (3rd ed.). St. Louis, MO: Elsevier.

Matheson, D., Iverson, S., Neuwelt, P., Gray, B., Tunoho, M., James, K., Loring, B., ... \& Reidy, J. (2013). Towards an equitable primary health care policy for all New Zealanders. (Ist ed.). Retrieved from https://www.nzno.org.nz/get_involved/consultation/ artmid/4775/

Ministerial Advisory Committee. (200I). The report of the Ministerial Advisory Committee on a Māori perspective for the Department of Social Welfare. Retrieved from https:// www.msd.govt.nz/documents/about-msd-and-our-work/publications-resources/ archive/1988-puaoteatatu.pdf

Ministry of Health. (2000). Eight health gain priority areas for Māori health 1999/2000. Wellington, New Zealand: Māori Health Operating Group.

Ministry of Health. (2013). The health of Maori adults and children. Retrieved from http://www.moh.govt.nz/NoteBook/nbbooks. nsf/0/9IF76502A6IE4F3DCC257B4400040D92/\$file/health-maori-adults-children-summary.pdf

Ministry of Health. (2016). Emergency department use 20/4/15. Wellington, New Zealand: Author.

Ministry of Health. (2018a). Socioeconomic indicators. Retrieved from https://www.health.govt.nz/our-work/populations/maorihealth/tatau-kahukura-maori-health-statistics-nga-awe-o-te-hauora-socioeconomic-determinants-health/socioeconomicindicators

Ministry of Health. (20l8b). Achieving equity in health outcomes highlights of important national and international papers. Retrieved from https://www.health.govt.nz/system/files/documents/publications/achieving-equity-in-health-outcomes-important-paperhighlights-novl8_l.pdf

Ministry of Health. (2019a). Achieving equity in health outcomes summary of a discovery process. Retrieved from https://www. health.govt.nz/system/files/documents/publications/achieving-equity-in-health-outcomes-summary-of-a-discoveryprocess-30jul2019.pdf

Ministry of Health. (2019b). Wai 2575 Māori health trends report. Retrieved from https://www.health.govt.nz/system/files/ documents/publications/wai-2575-maori-health-trends-report-04mar2020.pdf

Ministry of Health. (2019c). Health and independence report 2018. Wellington, New Zealand: Author.

Ministry of Health. (2020). Whakamaua: Māori health action plan 2020-2025. Wellington: Author. Retrieved from https://www. health.govt.nz/system/files/documents/publications/whakamaua-maori-health-action-plan-2020-2025-2.pdf

Ministry of Health. (2016). New Zealand health strategy. Wellington. Author. Retrieved from https://www.health.govt.nz/publication/ new-zealand-health-strategy-2016

New Zealand Mental Health and Addiction Inquiry. (2018). He ara oranga: report of the government inquiry into mental health and addiction. Retrieved from https://mentalhealth.inquiry.govt.nz/assets/Summary-reports/He-Ara-Oranga.pdf

New Zealand Parliament. (2009). New Zealand health system reforms. Retrieved from https://www.parliament.nz/en/pb/ research-papers/document/00PLSocRP0903I/new-zealand-health-system-reforms

Nursing Council of New Zealand. (20II). Guideline for cultural safety, the Treaty of Waitangi and Māori health in nursing education and practice. Retrieved from pro.healthmentoronline.com/assets/Uploads/refract/pdf/Nursing_Council_cultural-safetyl I.pdf

Nursing Council of New Zealand. (20I2). Competencies for registered nurses. Retrieved from https://www.nursingcouncil.org.nz/ NCNZ/nursing-section/Registered_nurse.aspx

Pōmare, E. (1995). Hauora: Māori standards of health. Wellington, New Zealand: Te Rōpū Rangahau Hauora a Eru Pōmare/Eru Pōmare Māori Health Research Centre.

Reid, P. \& Robson, B. (2006). The state of Māori health. In M, Mulholland and contributors (Ed.). State of the Māori Nation; Twentyfirst-century issues in Aotearoa (pp. 17-31). Auckland, New Zealand: Reed Publishing. 
Robinson, K., Kearns, R., \& Dyck, I. (2007). Cultural safety, biculturalism and nursing education in Aotearoa/New Zealand. Health \& Social Care in the Community, 4(6), 371-380. doi: I0.1 III/j.1365-2524.1996.tb00084.x

Ross, J. (2017). 'Place' matters to Rural Nurses: A study located in the rural Otago region of New Zealand [Doctoral dissertation, University of Otago]. Semantic Scholar https://pdfs.semanticscholar.org/f4a6/IOf544ccee7f8bb3709da 0 I29bI55f5faa63.pdf

Statistics New Zealand. (1994). New Zealand now: Māori (Ist ed.). Wellington, New Zealand.

United Nations. (2009). Department of economic and social affairs: State of the world's indigenous peoples. Retrieved from https:// www.un.org/esa/socdev/unpfii/documents/SOWIP/

Wepa, D. (Ed). (2015). Cultural safety: In Aotearoa New Zealand (2nd ed.). Melbourne, Australia: Cambridge University Press.

Whitehead, M. (1992). The concepts and principles of equity and health. International Journal of Health Services, 22(3), 429-445. doi: 10.2190/9861-lhq6-2vte-yrrn

World Health Organisation (2020). Equity. Retrieved from https:/www.who.int/healthsystems/topics/equity/en/ 